\title{
The Parenthood Happiness Puzzle: An Introduction to the Special Issue
}

\author{
Hans-Peter Kohler ${ }^{1} \cdot$ Letizia Mencarini $^{2}$
}

Published online: 22 August 2016

(C) Springer Science+Business Media Dordrecht 2016

\begin{abstract}
Contrary to conventional wisdom, recent studies argue that parenthood is not necessarily related to higher parental subjective well-being (SWB). However, parenthood remains an important aspect of adults' lives, also in highly developed societies where childbearing has become optional, financially expensive and affecting other goals in life. Whereas a great deal of effort has been put into answering why fertility is low in so many developed countries, one may even ask why is it not even lower. The answer is not obvious but stems from the fact that, to date, the relationship between fertility and SWB has been understudied and the mechanisms at work are not well understood. This special issue makes a step forward in this line of research, providing a coherent set of papers addressing different dimensions of the relationship between fertility and SWB and its mechanisms, starting from a demographic perspective, but integrating theories and research results from other disciplines. The collection of papers assesses the effect of the birth of a child on the individual SWB from angles still unexplored with the idea that the effects of fertility on individuals' SWB are diverse depending on individual, couple and country contextual factors.
\end{abstract}

Keywords Subjective well-being $\cdot$ Parenthood $\cdot$ Low fertility

Conventional wisdom arguably suggests that parenting is satisfying for parents: individuals in early to mid-adulthood often claim to look forward to entering

Letizia Mencarini

letizia.mencarini@unibocconi.it

1 Department of Sociology and Population Studies Center, University of Pennsylvania, Philadelphia, PA, USA

2 Dondena Centre for Research on Social Dynamics and Public Policy, Bocconi University, Via Roentgen 1, 20136 Milan, Italy 
parenthood and having children. Even in highly developed societies, where childbearing has become optional, financially expensive and is often associated with considerable trade-offs in terms of professional careers and pursuing other goals in life, parenthood has remained an important aspect of the lives of most adults. An overwhelming majority of young adults believes that parenthood will be fulfilling, and in the US, this fraction has even been increasing during the 1970s-1990s (Thornton and Young-DeMarco 2001). Mothers report about intense emotions evoked by their children (Preston and Hartnett 2008), and parents who feel "madly in love" with their children and report high levels of agreement with statements such as "I have an overwhelming love for my children unlike anything I feel for anyone else" (Erickson et al. 2005). Moreover, despite declines of the fertility rates to below replacement levels in virtually all developed countries and to "lowest-low fertility levels" in many Southern, Central and Eastern European countries during the 1990s, childlessness is relatively uncommon (often below $20 \%$; Kohler et al. 2002; Sobotka 2004). Interpreting these trends in the light of the Second Demographic Transition theory, which de-emphasizes families and highlights self-fulfilment as an increasingly important life goal (van de Kaa 1987), contemporary patterns of childbearing in high-income countries seem to confirm the conventional wisdom that parenthood-that is, the fact of having at least one child - is rewarding for individuals and that having children, generally one or two, rarely more than three, would tend to increase individuals' subjective well-being (SWB).

In sharp contrast to the conventional wisdom about the effect of parenthood on happiness, the popular press has questioned the notion that children and childrearing increase the subjective well-being of their parents. In a relatively recent New York Magazine article, Senior (2010) ${ }^{1}$ summarized the relationship between parenthood and happiness as "All Joy and No Fun: Why Parents Hate Parenting", pointing to the fact that children often "expose the gulf between our fantasies about family and its spikier realities; [they] mean parting with an old way of life, one with more freewheeling rhythms and richer opportunities for romance". In other words, parenting may be much less rewarding in terms of SWB than expected by conventional wisdom.

How can we reconcile these different perspectives on the relationship between parenthood and happiness? In trying to answer the question whether children bring happiness in life, this special issue reverses the most often asked question about contemporary fertility trends in developed countries. While much of the existing literature on low fertility focuses on the questions of why fertility is low or lowest low in many European countries, one may provocatively ask the reverse question: Why is not fertility even lower, especially in light of the claims that apparently parenthood is not necessarily related to better SWB of the parents? We currently do not have an empirically founded, satisfactory and comprehensive answer to this question. In part, this is due to the fact that, to date, the relationship between fertility and SWB has been understudied and mechanisms at work have not been fully identified.

\footnotetext{
${ }^{1}$ See also Senior (2014), a New York Times best-seller book.
} 
This special issue of the European Journal of Population makes an important contribution in furthering our understanding about the interrelation between fertility behaviour and SWB. Starting from a demographic perspective, but integrating theories and research results from other disciplines, in particular psychology, sociology and economics, this SI provides a coherent set of papers addressing different dimensions of the overarching question. By doing so, the SI goes beyond studying the simple relationship between childbearing and SWB, aiming at understanding the mechanisms through which children influence SWB covering both individual (biological and/or psychological) or external factors (social responses). The collection of papers therefore assesses the effect of the birth of a child on the individual SWB from angles still unexplored, with the idea that effects of fertility on individuals' SWB may be diverse depending on individual, couple and country contextual factors.

\section{Children Matter for Parents' Subjective Well-Being}

Fertility is certainly a core theme in demography, but its genesis has changed substantially in post-transitional low-fertility societies. Childbearing in high-income settings with relatively easy access to contraception is in most cases a deliberate choice by individuals and couples. At the same time also in these societies, both timing and quantum "errors" in childbearing are frequent. For instance, about $51 \%$ of pregnancies to women in the US nowadays are reported to be mistimed or unwanted at the time of conception (Finer and Zolna 2013). This rather high rate of unintended pregnancies-at least $30 \%$ or higher-is also found to occur among women aged above 35, among married women and college-educated women, indicating that mistimed or unwanted pregnancies are not necessarily restricted to young (teenage), poor or otherwise disadvantaged strata of the population. In comparison with other advanced countries, however, the US is often seen as an outlier in terms of its high levels of mistimed or unwanted childbearing and desired fertility is likely to represent a larger fraction of overall fertility in most European or Asian low-fertility countries (Sedgh et al. 2014).

The choice to have a child is clearly intertwined with a range of other consumption and life cycle decisions, from which individuals also derive well-being and satisfaction: labour force participation, careers, leisure time, travel and mobility, material consumption and other aspects of self-realization emphasized in the Second Demographic Transition theory. And clearly, there has been a sea of change: fertility in virtually all high-income countries is low (near or below replacement level). But parenthood has not "gone out of fashion". Despite the fact foregone parenthood is nowadays a commonly accepted choice in highly developed countries; parenthood continues to be far more common than childlessness even among relatively young cohorts. And an increasing number of individuals craves for the experience of parenthood, when for various impediments (infecundity, lack of partner, or same sex partner), it cannot be materialized, arising new controversial phenomena, such as assisted reproduction techniques and gestational surrogacy (e.g. Leridon and Slama 2008). 
Looking across research in psychology, economics and demography, there is still no consensus concerning the effect of childbearing on individuals' SWB, neither in terms of the direction and the magnitude, nor on the causal determinants for the relationship. The effect of (another) child can be positive or detrimental, depending on individual characteristics (i.e. gender, parents' and children's age and socioeconomic status) and contextual factors (i.e. cultural and institutional context).

While there continues to be a puzzle about the parenthood-happiness relationship, a rapidly growing recent literature-including also this SI-has significantly expanded our understanding of the relationship between having children and the SWB of parents. This progress was partly facilitated by the availability of longstanding panel data (i.e. German SOEP, Australian HILDA, British BHPS and US panels, but also newer ones that were conducted in Switzerland, Poland, Russia, Japan and Korea). These surveys provide powerful tools for analysing the dynamics of life events and SWB, including anticipation, reaction and adaptation. In other words, they allow analysis of SWB before, during and after the childbearing event. As a result, the problem of reverse causality can be tackled and we can start understanding the effects of childbearing for SWB.

Psychologists assert that a large fraction of variation in well-being stems from social or biological endowments, and although life events may either make individuals happier-or less happy-depending on the nature of the event, the change is only transitory. In the now-famous metaphor of Brickman and Campbell (1971), each individual is on a "hedonic treadmill", a feature also highlighted by Easterlin (1973) and Easterlin et al. (2010), who showed that despite there being a positive relationship between income and happiness, the latter does not increase over time even if income does. The existence of a hedonic treadmill would imply that if people continue to adapt to their life-course circumstances, objective improvements yield no real benefits and worsened conditions will not necessarily translate into a lower assessment of well-being. Thus, every individual is presumed to have a predefined happiness level that he or she returns to as time goes by Csikszentmihalyi and Hunter (2003), Kahneman et al. (1999) and Williams and Thompson (1993). The direct implication, if this theory is valid, is that both individuals and policy-makers cannot actually do very much to improve the wellbeing of citizens in general or parents in particular. Many empirical studies build up under the set-point theory and support the prediction that objective circumstances appear limited in magnitude, scope and particularly the duration of their effects on psychological well-being. In the long run, it would instead reflect stable characteristics of the individual (Costa et al. 1987; De Neve et al. 2010; Lykken and Tellegen 1996). What gives demography a special place, is that recent studies consistently show that certain life events, including childbearing, do have long-lasting effects on subjective well-being. Not only do changes in family-related domains seem more enduring than in domains related to their material standard of living, i.e. income (Argyle 2001; Diener et al. 1999; Veenhoven 1993), but also a number of psychological studies (i.e. Sheldon and Lucas 2014), as well as demo-economic studies (Kohler et al. 2005; Margolis and Myrskylä 2011; Zimmerman and Easterlin 2006), consistently demonstrate that important life events do indeed bring about long-lasting shifts of SWB. Recently, demographers have also demonstrated that 
subjective well-being plays a role not only as an outcome following demographic events-it also drives demographic outcomes (i.e. Le Moglie et al. 2015).

Whereas demographic processes are arguably important for SWB, demographers do stand to learn a great deal from the plethora of theories concerning SWB found within psychology and more generally the social sciences. Demography can contribute to these open questions concerning parenthood and SWB by focussing on demographic processes. For example, in the economic literature, the effect of children on life satisfaction has been found to be negative. But the modelling and analyses that lie behind this finding have been rather indirect with often rather generic measures of subjective well-being and fairly crude indicators of individual childbearing (like the number of children or in some cases age of children). Actual children born is an outcome of a process that often involves significant planning, a fact reflected by the now many studies about fertility intentions (see Bachrach and Morgan 2013, for a recent discussion). Moreover, the well-being associated with children will necessarily depend on the children (e.g. their health or behavioural problems) and perhaps even the age of the parents. In fact, demographic studies have shown that subjective well-being also increases in anticipation of childbearing after which it then tends to decline (e.g. Myrskylä and Margolis 2014). This means that the effect of childbearing on subjective well-being critically depends on the time where subjective well-being is measured. If measured at the time of childbearing, the effect may indeed be negative. Taking the time and the dynamics seriously will give a different picture in terms of SWB. In a similar vein, these studies found that the process of having the second child (or even children of higher order) is very different from having the first. This is also reflected in terms of SWB. Becoming a parent first time around appears to have a very different impact on life satisfaction compared to having a subsequent child. Moreover, the spacing also matters, in that SWB being associated with becoming parents first time around, and affects the likelihood of fertility progression. In sum, once childbearing is considered as a process, the linkages to well-being become much more complex showing at the same time its necessity to get a better grasp on the processes at stake and its subsequent outcomes.

\section{A New Generation of Studies}

The recent wave of new studies on the parent happiness puzzle has been made possible through the availability of long panels with repeated measures of subjective well-being allowing methodologically sophisticated analyses of the causal effects and pathways underlying the parenthood-happiness relationship.

While some studies find a positive association between parenthood and happiness (Aassve et al. 2012; Kohler et al. 2005; Kotowska et al. 2010), other empirical studies have shown that having children has either non-significant or negative effects on SWB (Clark and Oswald 2002; Clark et al. 2008; Frey and Stutzer 2000; McLanahan and Adams 1987; Myrskylä and Margolis 2014; Nomaguchi and Milkie 2003). This inconsistency in findings may result from the fact that the effect of children on SWB depends on several characteristics, not always considered in the 
studies - or accounted for correctly in longitudinal framework-i.e. the number and age of children (Clark et al. 2008; Kohler et al. 2005; Myrskylä and Margolis 2014), the personality traits and the "initial" pre-birth happiness level (Kohler et al. 2005; Myrskylä and Margolis 2014) or the stage in the life course of the parents (Margolis and Myrskylä 2011) or the context (Aassve et al. 2012, 2015).

However, it is not unexpected that during the life course, children can bring both happiness and misery, since some of the benefits (and costs) from having children are short term and others emerge only after many years. One important point, when the question is how children influence parental well-being, it is the possibility to analyse individual changes over time instead of only comparing parents with the childless; otherwise, the analyses may be biased by genetic factors, personality, or other unobserved or difficult-to-measure fixed characteristics, such as orientation towards career versus family, which may be associated with both fertility behaviour and subjective well-being (Alvergne et al. 2010; De Neve et al. 2010; Myrskylä and Margolis 2014; Rodgers et al. 2001). Myrskylä and Margolis (2014) document how the happiness trajectory of parents differs greatly by age at parenthood, socioeconomic status, gender, parity, marital status and context.

The collection of papers belonging to this special issue follow up on this new literature, drawing on several rich longitudinal surveys, namely GSOEP (German Socioeconomic Panel, since 1984), BHPS (British Household Panel Study, since 1991), HILDA (Household, Income and Labor Dynamics in Australia, since 2001), SHP (Swiss Household Panel since 1999), and also from recent comparative (even though cross-sectional) rich surveys, namely Gallup World Poll (here 163 countries analysed) and European Social Survey (here 16 countries analysed).

The first paper, by Arnstein Aassve, Bruno Arpino and Nicoletta Balbo, adopts a couple perspective on the fertility behaviour. They notice how this is neglected in the SWB-fertility literature, which tends to focus on individuals only, or rather, respondents' well-being. If childbearing is the result of a joint partners' decisionmaking process, the subjective well-being of both partners should matter for stepping into parenthood, and a couple perspective can bring insights into the relationship between SWB and couples' childbearing. In fact, they find not only that women's own happiness matters more than that of their partners for the transition to the first child, but also that spouses' happiness reinforces each other and has a multiplicative effect on SWB.

The second paper, by Anna Matysiak, Letizia Mencarini and Daniele Vignoli, builds on the existing inconsistent literature on the effect of children on parents' SWB (measured as overall life satisfaction), sustaining that presumably important moderating characteristics are not considered in previous studies. They point to the intensity of the work-family conflict experienced by parents, arguing that the negative (or positive) effect of children on parent's SWB can be caused by work and family tension (reconciliation). Including the self-reported work-family conflict allows for capturing not only individual experiences with combining paid work and care (including contextual factors, such as access to external childcare services or support by partners, relative and friends or flexibility of working hours) but also the psychological reaction to these experiences. The results provide support to the hypothesis that a decline in SWB after the birth of a child does not happen to all 
parents, but only to those-mothers in particular-who face a substantial workfamily conflict.

The third paper by Anne Roeters, Jornt Mandemakers and Marieke Voorpostel addresses the heterogeneous conditions under which parenthood is more or less beneficial for individual well-being, investigating the role of participation of mothers and fathers in leisure and paid work during the transition to parenthood. They found that the effect of SWB, here measured as the absence of negative emotional states such as depression, is moderated by individuals' lifestyle before the transition to parenthood. Only for fathers with high pre-birth level of leisure activities, parenthood reduced well-being, as well as the (average) beneficial effect of motherhood is reduced for those women who combined before motherhood high levels of leisure activities with long working long hours.

The fourth paper, by Rachel Margolis and Mikko Myrskyla, inquires whether the sex of children affects the happiness of their parents. Building on well-established findings across European countries shows that sex preferences for the first child are absent, but strong preference for opposite-sex children at the next parity exists, they hypothesize that a second child of the same sex than the first would decrease the SBW of parents as well as their children. As expected-although sex preferences influence fertility, i.e. the third parity progress ratio-parental happiness does not depend on the sex of the first child and only weak evidence is found on the fact that two boys decrease parental happiness. On the basis of these results, the authors suggest that parents are happy with the children they have, regardless of their sex.

The fifth paper, by Francesca Luppi, investigates how the subjective experience of the first birth may influence the timing of the transition to the second child. Also her findings call again for a consideration of gender roles and especially on mothers' difficulties in reconciliation between family and work. Results show higher and quicker transition to the second child of partners adopting traditional gender roles or-among dual earner couples-those will less difficulties in reconciling work and family.

The last paper, by Sophie Centre, Andrew Clark and Claudia Senik, conducts a dual analysis of the relationship between parenthood and subjective well-being, to further our understanding of the parenthood subjective well-being paradox, i.e. the fact that in a certain number of countries parenthood tends to be associated with lower happiness rather than higher as found in most countries. First, studying the link over a wide range of countries, they conclude that according to basic crosscountry correlations, there is a sharp contrast between developing and developed countries. They find the link between childbearing and SWB is positive only in developed countries, i.e. where fertility is largely optional. In an additional step, using German longitudinal data, they further examine the decision-making process of parenthood, providing evidence of a positive selection into parenthood, whereby happier (or more satisfied) people are more likely to have children. Showing that the satisfaction gap in favour of future parents is apparent up to five years before the first childbirth-and does not entirely reflect better socio-economic circumstances-they question the positive relationship between SWB and fertility, sustaining that may be due to self-selection into parenthood rather than to a causal impact of children on parents' happiness. 


\section{The Still Unexplored Issues of Fertility and Subjective Well-Being}

Billari (2009) and Billari and Kholer (2009) argued some time ago that the "quest for happiness", in which children play a key role, is the "commonality" that may provide an enhanced understanding of fertility behaviour and differentials in contemporary societies. These studies were also indirectly saying that there is not a universal effect of parenthood on subjective well-being, but it may well depend on the opportunities for parents-mothers in particular-to reduce the costs of children. Those costs are inevitably linked also to macro-characteristics of the country where couples reside, which may have an impact on their assessment of happiness associated with childbearing.

While increasingly recognized as being an important aspect, the heterogeneity in the effect of childbearing on parental SWB continues to be inadequately discussed and analysed. Only some of the recent literature has started to change this. On the one hand, there is an emerging consensus that certain groups of the population perceive the cost of parenting in different ways depending on their socio-economic status, social support, gender and country of residence, on top of preferences and attitudes. Parenting joy or stress would therefore be greater for some groups than others. On the other hand, there is increasing agreement in stating that a solid understanding of the various mechanisms through which parenting affects wellbeing is still missing. These pathways could include both biological (i.e. different hormonal level by sex around childbirth) and social responses. Important is also the fact that mothers are still usually the primary caregiver, making them more vulnerable to work-family conflicts compared to fathers. More detailed information about these individual and couple's characteristics are therefore essential to further understanding of the social mechanisms behind the childbearing-SWB relationship (Brewster and Rindfuss 2000; Kohler et al. 2002; Kohler 2012; Myrskylä and Margolis 2014; Neyer and Andersson 2008). The fact that in some comparative studies, mothers appear to be more strongly affected by country of residence seem to confirm the macro-level hypothesis that predicted happiness is positively associated with institutional and cultural factors that increase the compatibility between work and motherhood. Working status and household income interacted with childbearing are strongly associated with mother's happiness. Having a large family while working is associated with less happiness for mothers, while the opposite is true for men (Aassve et al. 2012, 2015; Billari and Kholer 2009). While the papers in this special issue make important contributions in this respect, future research will also have to capture better the manifold ways in which labour market flexibility, social security and individual welfare, gender and economic equality, societal human capital levels, and social and family policies can facilitate a relatively high satisfaction with parenthood in advanced societies.

Given the heterogeneity of institutional, cultural and policy contexts across developed countries, further research is required to investigate the different mechanisms that may underlie these heterogeneous implications of children for well-being (see also Kohler 2012). In a recent comparative paper based on crosssectional European Social Survey data from 28 countries, Aassve et al. (2015) 
observe that fertility is higher in countries where the average happiness is high, the prime example being the Nordic countries. At the other end, there are East European countries, where happiness is low but also fertility is low. This feature is crystallized when in the analysis, they differentiate parents against non-parents, but in particular when done so for mothers and non-mothers. In societies where institutional development is highly advanced, individuals are not only happier in general, but it turns out that parents are always happier than non-parents. This finding holds also for women, and indeed, mothers are significantly happier than non-mothers, but only in the most advanced societies. The opposite is the case in those countries where development is lower. The fact that fathers are always happier than childless men-independent of the level of development-suggests very clearly that the gender perspective matters in critical ways. In essence, it means that in highly developed countries, happiness associated with childbearing is consistent across gender, whereas it is not in countries where appropriate institutions for reconciling parenthood and working are less developed. This argument bears a clear resemblance to the work by McDonald (2000, 2013) and Esping-Andersen (2009), who argue that low fertility comes about because of a mismatch between equity considerations, and actual experienced equality between parents - the latter depending directly on the institutional setting. Aassve et al. (2015) argue that this can equally be looked upon as a mismatch between aspirations and attainment. As argued in psychology, such mismatch will likely yield lower SWB (Lewin et al. 1944). What matters for our understanding of fertility change is that as women gain ever higher education, and their aspirations change, institutions also need to change to ensure consistency between those aspirations and what can be attained. Fertility in the new emerging gender egalitarian societies will be higher because the institutional setting enables women to have working careers and children at the same time. This change affects the parenthood-SWB relationship because the presence of "appropriate" institutions lowers the potential gap between individual aspirations and their attainments. Consequently, egalitarian societies would be expected to both have higher fertility and higher subjective well-being. The same argument holds for the malebreadwinner model of the 1960s and 1970s, where lower levels of education among women would be consistent with couples specializing between market and household production, hence giving consistency between aspirations and attainment, and hence producing higher subjective well-being. Following this argument, happiness derived from parenthood is lower when institutions do not correspond to or do not adapt sufficiently to new preferences. All of these suggest that the relationship between fertility and SWB critically depends on the way institutions evolve-or perhaps-fail to evolve.

It is useful to end this introduction with some reflections on outstanding issues mentioned and consequently make suggestions for directions for further research. Clearly, the open issue concerning contexts (and welfare regimes), and the way they shape the parenthood-happiness relationship, is predominantly driven by a lack of data suited to study these associations, namely high quality, prospective data covering different geographical regions. The majority of current studies relies on a rather limited set of longitudinal surveys, namely Germany, UK and Australia. 
Although Switzerland, Russia, Japan, Korea, Poland, USA have also panels, the available information is much more limited and does not cover longer time periods. The relationship between fertility and SWB in terms of context remains therefore largely unexplored for the majority of developed countries. Given the current state of data availability, it is difficult to verify the hypothesized differences by welfare regimes, i.e.-for instance-between Scandinavian and Southern European countries. Investments in data collection are therefore crucial to further our understanding on childbearing and SWB.

Current gaps in global data on fertility and SWB also imply that little is known about this relationship in middle-income countries or developing countries. In these contexts, due to the central but rapidly changing roles of families, the relationship between childbearing and SWB might even be of more relevance. For example: to what extent does childbearing affect mothers' or fathers' SWB when very different social norms, and opportunities, about reproduction and family life apply? This line of research seems very promising, not least because more economic studies of fertility and poverty (or consumption) are not fully able to explain why fertility remains high. Does having many children lead to higher SWB, despite happiness being apparently negatively correlated with poverty? Clearly, data availability poses a considerable challenge for addressing these questions. There are some longitudinal surveys in place, and for example, studies based on either the Ethiopian Rural Household Panel (EDHS 2011), or the Malawi Longitudinal Study of Families and Health (MLSFH, Kohler et al. 2015) could provide new and highly interesting insights that help us in understanding fertility patterns, adopting the "lens" of SWB, in these societies.

Last, it is worthwhile pointing out that so far, the vast majority of studies considers how children tend to affect parents' subjective well-being. An interesting extension of this line of study would be to ask to what extent children's well-being, and their cognitive and social development is affected by parents' subjective wellbeing. Similarly, one can also hypothesize that parents' subjective well-being is affected by the subjective well-being of their children. The latter hypothesis would suggest if children are developing well, and they are happy, and then this also spills over onto the reported well-being of the parents. Are parent and child well-being complementary or are there trade-off? These questions seem paramount in further research.

This special issue makes an important start by pursuing this line of research questions - the main idea being that there is not $a$ universal effect of fertility on SWB (nor vice versa, of SWB on fertility). So far the literature has had a tendency to emphasize average effects. The demographic perspective adopted in this special issue clearly shows that there is still a lot to explore. It demonstrates diverse findings which depend on a range of (demographic) characteristics-including parity, the individual, couple or country contextual factors.

Acknowledgment Letizia Mencarini gratefully acknowledges financial support from the European Research Council under the European ERC Grant Agreement no StG-313617 (SWELL-FER: Subjective Well-being and Fertility). 


\section{References}

Aassve, A., Goisis, A., \& Sironi, M. (2012). Happiness and childbearing across Europe. Social Indicators Research, 108, 65-86.

Aassve, A., Mencarini, L., \& Sironi, M. (2015). Institutional change, happiness and fertility. European Sociological Review, 31(6), 749-765.

Alvergne, A., Jokela, M., \& Lummaa, V. (2010). Personality and reproductive success in a high-fertility human population. Proceedings of the National Academy of Sciences, 107(26), 11745-11750.

Argyle, M. (2001). The psychology of happiness (2nd ed.). London: Routledge.

Bachrach, Christine A., \& Morgan, S. Philip. (2013). A cognitive-social model of fertility intentions. Population and Development Review, 39(3), 459-485.

Billari, F. C. (2009). The happiness commonality: Fertility decision in low-fertility settings. In UNECE (Ed.), How generations and gender shape demographic change (pp. 7-38). Geneva: United Nations.

Billari, F.C., \& Kholer, H.P. (2009). Fertility and happiness in the XXI century: Institutions, preferences, and their interactions. Paper presented at the XXVI IUSSP international population conference in Marrakech, Morocco, 27 September-2 October, 2009.

Brewster, K. L., \& Rindfuss, R. R. (2000). Fertility and women's employment in industrialized nations. Annual Review of Sociology, 26, 271-296.

Brickman, P., \& Campbell, D. T. (1971). Hedonic relativism and planning the good society. Adaptation level theory: A symposium. New York: Academic Press.

Clark, A. E., Diener, E., Georgellis, Y., \& Lucas, R. E. (2008). Lags and leads in life satisfaction: A test of the baseline hypothesis. The Economic Journal, 118(529), 222-243.

Clark, A. E., \& Oswald, A. J. (2002). Well-being in panels. Working Paper, University of Warwick, United Kingdom.

Costa, P. T., Zonderman, A. B., McCrae, R. R., Cornoni-Huntley, J., Locke, B. Z., \& Barbano, H. E. (1987). Longitudinal analyses of psychological well-being in a national sample: Stability of mean levels. Journal of Gerontology, 42, 50-55.

Csikszentmihalyi, M., \& Hunter, J. (2003). Happiness in everyday life: The uses of experience sampling. Journal of Happiness Studies, 4(2), 185-199.

De Neve, J., Christakis, N., Fowler, J., \& Frey, B. (2010). Genes, economics, and happiness. Institute for Empirical Research in Economics (University of Zurich) Working Paper No. 475, pp. 1-46.

Diener, E., Suh, E. M., Lucas, R. E., \& Smith, H. (1999). Subjective well-being: Three decades of progress. Psychological Bulletin, 125, 276-302.

Easterlin, R. A. (1973). Does money buy happiness? Public Interest, 30, 3-10.

Easterlin, R. A., McVey, L. A., Switek, M., Sawangfa, O., \& Smith Zweig, J. (2010). The happinessincome paradox revisited. PNAS, 107(52), 22463-22468.

Erickson, E. G., Martha, F., \& Aird, E. G. (2005). The motherhood study: Fresh insights on mothers' attitudes and concerns. Research Report, Motherhood Project and the Mothers' Council of the Institute for American Values. http://www.motherhoodproject.org.

Esping-Andersen, G. (2009). The incomplete revolution: Adapting to women's new roles. Cambridge: Polity Press.

Finer, L. B., \& Zolna, M. R. (2013). Shifts in intended and unintended pregnancies in the United States, 2001-2008. American Journal of Public Health, 104(1), 43-48.

Frey, B. S., \& Stutzer, A. (2000). Happiness, economy and institutions. The Economic Journal, 110(466), 918-938.

Ethiopia Demographic and Health Survey, EDHS. (2011). Final report. Central Statistical Agency, Addis Ababa, Ethiopia and ICF International, Calverton, Maryland, USA. http://dhsprogram.com/pubs/ pdf/FR255/FR255.pdf.

Kahneman, D., Diener, E., \& Schwarz, N. (Eds.). (1999). Well-being: Foundations of hedonic psychology. New York: Russell Sage Foundation.

Kohler, H.-P. (2012). Do children bring happiness and purpose in life? In W. B. Wilcox \& E. Kaufman (Eds.), Whither the child: Causes and consequences of low fertility (pp. 47-75). Boulder: Paradigm Publishers.

Kohler, H.-P., Behrman, J. R., \& Skytthe, A. (2005). Partner + children = happiness? The effects of partnerships and fertility on well-being. Population and development review, 31(3), 407-445.

Kohler, H.-P., Billari, F. C., \& Ortega, J. A. (2002). The emergence of lowest-low fertility in Europe during the 1990s. Population and Development Review, 28(4), 641-681. 
Kohler, H.-P., Watkins, S. C., Behrman, J. R., Anglewicz, P., Kohler, I. V., et al. (2015). Cohort profile: The Malawi Longitudinal Study of Families and Health (MLSFH). International Journal of Epidemiology, 44(2), 394-404.

Kotowska, I. E., Matysiak, A., Pailhe, A., Solaz, A., Styrc, M., \& Vignoli, D. (2010). Family and work. Second European quality of life survey. Dublin: Eurofound (The European Foundation for the Improvement of Living Conditions).

Le Moglie, M., Mencarini, L., \& Rapallini, C. (2015). Is it just a matter of personality? On the role of well-being in childbearing behavior. Journal of Economic Behavior and Organization, 117, 453-475.

Leridon, H., \& Slama, R. (2008). The impact of a decline in fecundity and of pregnancy postponement on final number of children and demand for assisted reproduction technology. Human Reproduction, 23(6), 1312-1319.

Lewin, K., Dembo, T., Festinger, L., \& Sears, P. S. (1944). Level of aspiration. In J. Mc. V. Hunt (Ed.), Personality and the behavior disorders. New York: Ronald Press.

Lykken, D. T., \& Tellegen, A. (1996). Happiness is a stochastic phenomenon. Psychological Science, $7(3), 186-189$.

Margolis, R., \& Myrskylä, M. (2011). A global perspective on happiness and fertility. Population and Development Review, 37(1), 29-56.

McDonald, P. (2000). Gender equity in theories of fertility transition. Population and Development Review, 26(3), 427-439.

McDonald, P. (2013). Societal foundations for explaining fertility: Gender equity. Demographic Research, 28(34), 981-994.

McLanahan, S., \& Adams, J. (1987). Parenthood and psychological well-being. Annual Review of Sociology, 13, 237-257.

Myrskylä, M., \& Margolis, R. (2014). Happiness: Before and after the kids. Demography, 51(5), 276-347.

Neyer, G., \& Andersson, G. (2008). Consequences of family policies on childbearing behavior: Effects or artifacts? Population and Development Review, 34(4), 699-724.

Nomaguchi, K. M., \& Milkie, M. A. (2003). Costs and rewards of children: The effects of becoming a parent on adults' lives. Journal of marriage and family, 65(2), 356-374.

Preston, S. H., \& Hartnett, C. S. (2008). The future of American fertility. NBER Working Paper 14498. http://www.nber.org/papers/w14498.

Rodgers, J. L., Kohler, H.-P., Kyvik, K., \& Christensen, K. (2001). Behavior genetic modeling of human fertility: Findings from a contemporary Danish twin study. Demography, 38(1), 29-42.

Sedgh, G., Singh, S., \& Hussain, R. (2014). Intended and unintended pregnancies worldwide in 2012 and recent trends. Studies in Family Planning, 45(3), 301-314.

Senior, J. (2010). All joy and no fun. Why parents hate parenting, New York Times Magazine, 10th July 2010.

Senior, J. (2014). All joy and no fun: The paradox of modern parenthood. New York: HarperCollins.

Sheldon, K. M., \& Lucas, R. E. (Eds.). (2014). Stability of happiness: Theories and evidence on whether happiness can change. Amsterdam: Elsevier.

Sobotka, T. (2004). Postponement of childbearing in Europe. Amsterdam: Dutch University Press, Population Studies Series.

Thornton, A., \& Young-DeMarco, L. (2001). Four decades of trends in attitudes toward family issues in the United States: The 1960s through the 1990s. Journal of Marriage and Family, 63(4), 1009-1037.

Van de Kaa, D. J. (1987). Europe's second demographic transition. Population Bulletin, 42, 1-59.

Veenhoven, R. (1993). Happiness in nations: Subjective appreciation of life in 56 nations 1946-1992 RISBO. Rotterdam: Erasmus University Rotterdam.

Williams, D. E., \& Thompson, J. K. (1993). Biology and behavior: A set-point hypothesis of psychological functioning. Behavior Modification, 17(1), 43-57.

Zimmerman, A. C., \& Easterlin, R. A. (2006). Happily ever after? Cohabitation, marriage, divorce, and happiness in Germany. Population and Development Review, 32(3), 511-528. 